\title{
The Relationship Between Organizational Culture and Administrative Creativity in Universities
}

\author{
Ibtisam Khalid Yahia Salama, Dr. \\ College of Education for Girls, University of Jeddah, Saudi Arabia
}

Doi: 10.19044/esj.2018.v14n4p146 URL:http://dx.doi.org/10.19044/esj.2018.v14n4p146

\begin{abstract}
The organizational culture is a critical and coral factor in achieving the dimensions of the administrative creativity. It can be said that the improvement of the practice of organizational culture contributes as an effective factor in the level of administrative creativity in all its dimensions. The organizational culture plays a major role in all levels and activities within the administrative system. It contributes in the creation of the convenient organizational climate, which in turn works on improving and developing the performance in a convenient and efficient manner. It also helps in achieving the individual, collective and organizational objectives that is highlighted through embodiment, development of the modern values, orientations, behavior and standards which work on growth and development of job performance (Alkurdi, 2010). This paper will try to build a theoretical background on the organizational culture and administrative creativity in Saudi Arabia education socity. The main objective is to show the significance of organizational culture and administrative creativity and also the relationship between organizational culture and administrative creativity in universities. This research work showed how the organizational culture is important to the education filed in Saudi Arabia. It contributes in assisting the individual in problem solving and decision making. It helps to make a decisive decision in a relatively record time, and enable to discover problems in order to solve them.
\end{abstract}

Keywords: Organizational Culture, Administrative Creativity, international variations, Theoretical Background

\section{Introduction}

The fabric of organizational values and relationships composed by the organizational culture represent the most important component of the good organizational environment which qualifies the workers to develop the performance through accomplishing the administrative creativity, which is 
considered one of the most important objectives that organizations sought to accomplish in today's world. Bruise (2016) pointed that today's organizations lives in changing and complicated circumstances, making their need of administrative creativity an urgent one, as the managers who manage today's organizations have to be keen to grow and develop workers' capabilities of contributing to problem solving and participating in decision making and generating ideas.

The administrative creativity includes a set of resources based on the human element and knowledge. Being ordered and organized in steps and phases of activities which are being approved to achieve creations in the form of a product or a service or a system. (Gapar \& Mabic, 2014). Shagoura (2012) added that the renovation is considered the essence of the administrative creativity of any organization, making it an urgent need. It contributes in improving the capabilities and generation of ideas. It is coping with the modern technical developments, problem solving and participating in making the proper decisions in the proper time.

In additional to the above, it has become clear that today's organizations - due to the fast base international and domestic changes around them, and due to the ambiguity of that surrounding environment dictating the unpredictability of the future changes facing the organizations - they have to strive to identify their organizational culture and insure the compatibility of the components of that culture with the believes, values, orientations of the requirements of the times like knowledge and flexibility and development. Thence strengthening the administrative creativity through the suitable organizational atmosphere and providing the reasons and means which enable its employees to achieve that creativity.

The recent era organizations gained many characters attributed to humans, where organizations possessed the notional identity and the distinguished culture through which the general organizational atmosphere is labelled with the characters which organizations culture enjoys, as the organizational culture gives the organization the distinguished identity and contributes in developing the work team adaptation to the internal and external effects on work environment, likewise, it enables the higher administration to predict the recent and future workers behaviors making it capable of developing the workers' abilities to reach excellence and administrative creativity.

Hamza (2016) points that the organizational culture is a sub-pattern from the overall pattern of the organization, and that through the integration of the sub-patterns group, the organization acquires its identity discriminating it from other different organizations, and among the most important differences between one organization and another is the adoption of each organization of its own culture through shaping that culture according to the 
organization strategies and the capability of the higher administration to instill some values affecting the behavior of its individuals in a manner that serves the policies of that organization and make its performance more outstanding. Bruise (2016) adds that standing out organizations are the ones capable of creation and innovation in a permanent and continuous manner, and that the outstanding leaders are the ones capable of helping individuals in their organizations and benefiting from their creativity talents and investing their capabilities and energies, as several researchers and writers emphasized on the need of organizations for creation. Considering the relationship between the organizational culture and the administrative creativity, light will be shed on the concept of organizational culture and its significance and then on the administrative creativity, and demonstrating the relationship between the organizational culture and the administrative creativity in the universities.

\section{Concept of organizational culture}

The organizational culture can be defined as:" the set of believes and expectations and values which an organization members share" (Alamyan, 2004). Algarioti (2006) defines the organizational culture as: "The hypotheses and basic values which a certain group develops as to adapt and deal with the external and internal effects and which were agreed upon and on the necessity of teaching them to the new workers in the organization in order to realize things and think about them in a certain way that serves the official goals". Dawood (2011) sees that the organizational culture represents: "an integrated system of prevailing human behavior within the organization and approved by its individuals in dealing with each other including the thoughts and social customs which depend on knowledge and information transfer". Coley has divided the organizational culture according to the culture pattern where he puts it in two patterns, a clear or declared culture which is expressed by the administrative structure in place within the organization or the work rules and it's officially declared administration, and an implied or hidden culture which is actually practiced and in which there is a match between the prevailing values and orientations in the organizational culture and the values and orientations embraced or acted upon by the organization individuals (Mohammed and Mursi, 2012).

It is clear from the above that the organizational culture represents the set of values and believes and behaviors contributing in shaping the behavior of the workers in the organization and identifies their interaction manner among each other and the quality of reciprocal relationships and the trust to raise up the level of work performance. It is also clear that the organization culture is shaped in accordance with the workers behavior and their orientations, it is a final outcome of their believes and habits and rules and customs. As this culture dictates the basic frames for the organizational culture 
and making the workers move within them and act according to their context, as through them the workers behavior in the organization is directed, shaping the appearance of the organizational identity and the overall picture of the work.

\section{Significance of organizational culture}

The organizational culture is considered a main element of the elements composing today's organization; its importance is due to it being considered a philosophical and applied direction enabling the organization to cope with the modern changes and form futuristic visions through the organizational reference embodied by the organization culture. Almajali (2016) sees that the field of organizational culture is considered of the modern subjects introduced in the administration sciences books, and as the business organizations in the public and private sectors are witnessing developments and transformations in the field of information technology affecting the adaptation of those organizations to their environment, the significance of the organizational culture stands out through its basic role played and through which affecting the performance levels among the individuals, that reflects on the organization as a whole where each organization have its own special culture discriminating it from the rest of organizations.

What confirms the significance of the organizational culture "the fact it brings the workers behaviors within its conditions and help predicting their behavior and work on expanding their perceptions and enable them to face the events and deal with them". (Alamyan, 2010). Furthermore, Alalfi (2010) points that the significance of the organizational culture is due to its enabling its individuals to commitment and creation and participating in decision making, which pushed towards accomplishing an outstanding performance enabling the organization to accomplish its goals, While the weak culture is usually found due to the presence of a bad atmosphere that discourages the sharing and cooperation and serious work, it also results in the widespread of the carelessness and the severe slowness and some strange values and the presence some sort of organizational voiding, Alamyan (2010) sees that "in the weak culture individuals wander in opaque unclear paths and receive conflicting instructions and eventually fail to make convenient decisions in line with the values and orientations of the working individuals.

Emphasizing on the above it could be said that the significance of the organizational culture in overall goes back to the guiding and directing role it plays on the level of the individual workers and on the group working level within the organization environment as well as on the level of the organization as a part of the local and international community environment. 


\section{Administrative creativity}

The administrative creativity represents a direct reflection of the organization culture, as that culture strengthen the freedom of thought and accepts and encourages and financially supports the creative work, the level of creativity of the workers in the organization will rise accordingly. Osama (2012) defines the administrative creativity as an individual thinking process gathering brilliant knowledge with the creative work, touching various life fields and dealing with the reality and thriving towards the best, beside that the creativity is a result of the reaction of subjective or objective or characteristic or environmental or behavioral variables, led by outstanding persons. Furthermore, Ali (2011) sees that the administrative creativity represents the potential energy in a group of officials in different organizations, insuring the accomplishment of its goals with effectiveness and efficiency. Atiya (2009) points that the administrative creativity is a mixture of capabilities which enable the individual to produce a new, special and applicable idea, aiming at solving a problem or developing an existing system or finding a practical concept or method to execute the organization works in a manner ensuring the accomplishment of goals with efficiency and effectiveness.

In other words, the creativity is meant to create value or produce a new and useful idea, whether it is related to the production of a commodity or a service, or relates to the tools and procedures and operations, or relates to the strategies and policies and organizational programs, Bruise (2016) sees that the capability of the organization and its workers to excel and be creative and innovative depends on its ability to cope with the development, predetermining the necessity for the organization administration to develop its administrative concepts and methods to create the conditions for the human minds to create and innovate continuously through providing a suitable organizational atmosphere and an interactive environment contributing to the transfer of knowledge and accumulated acquired experiences helping to growth of creativity and development of the organization as an interactive entity.

The creativity process in not limited to developing the products or services or accomplishing goals, it rather extends to include problem solving, Both Naseer and Alfarawi (2015) point that creativity in problem solving does not come from only thinking about the problem, but also meet, enquire and listen to people, as creativity has two sides, one is conceptual and the other is perceptional, creative persons find an analytical way to work about creativity to benefit from the opportunity, they then interview the clients or employees to know their expectations and values and needs. Further to the above, it can be said that the creativity is more of a complicated phenomenon with many dimensions than being considered as a theoretical concept; as creativity from 
the theoretical point is referred to as the development or innovation of something new, it's the opposite to imitation; from the practical point, creativity is considered a behavior aiming at achieving a convenient and capable of development product, on the administrative level, creativity resembles a set of procedures and behaviors which lead to the improvement of the general atmosphere within the organization and activation of the creative performance through stimulating the workers to solve the problems and make decisions in a more creative manner and unconventional way of thinking; on the personal level of the workers in the organization, creativity reflects a mental capability differing from one person to the other and it may appear on the individual, group or organization level.

\section{Significance of administrative creativity}

The vital impact of the administrative creativity comes from what it achieves in development of work environment and accomplishment of organization goals, as through it the normal way of thinking is got rid of, and a new one is followed. Murad (2016) sees the administrative creativity as an integrated system shared by the administration and the organization members as managers and employees as well as the organization environment, the administration is considered the vital element in the performance of the organization, therefore it must evolve to accomplish its goals, given the elements of the creativity process, shows that its cornerstone is the employee from which and through which the organization is launched towards the administrative creativity.

Eid (2008) points that the administrative creativity is considered the core of any organization, the management scholars and practitioners unanimously agreed that today's organization lives through changing and complicated circumstances making it in critical need for administrative creativity, as it contribute to improve the workers' capabilities to generate the ideas and cope with the new technical developments and problem solving and participating in making the proper decisions in the proper time. Mousa (2013) sees that the positives provided by the administrative creativity phenomenon are represented in the improvement of organization services benefiting the organization and the individual, and the contribution in developing the intellectual and mental capabilities of the workers in the organization through giving them the opportunities to choose those capabilities and ideally exploiting the financial resources by using practical methods in line with the new developments, and the ability to strike a balance between the various developmental requirements and the available financial and human resources, and the good exploitation of the human resources and benefiting from their capabilities through providing the opportunities for them to search for new 
things in the work field and continuously improve the work guidelines in line with the surrounding changes.

\section{Organizational culture and administrative creativity relationship in universities}

The university is considered the most important higher education organization in today's world; it is also considered an ideal model for administrative organizations which are big in size and effectiveness in role in society both on individuals or corporation levels, due to the importance of the roles it plays every social, political and intellectual levels, "the university's mission and vision and objectives were only put in place to accomplish strategic goals including the educational product resembled in graduating masses of distinguished students in the various fields of science, and providing both theoretical and practical research services in the various branches of knowledge to actively contribute to providing several services to its surrounding societies " (Gapar \& Mabic, 2014).

"Administratively, universities are divided into a group of colleges and the departments represent the administrative units composing the college, therefore raising the attention to them and developing them and improving their output in recent years as they are the spine and cornerstone in the university establishment being the smallest organizational unit connecting its administrators and faculty members" (Kasab, 2007). Article 44 of the Higher Education and Universities Council regulation $(1436 \mathrm{H})$ states that: "The head of department, who must be a Saudi faculty members distinguished by his/her scientific and administrative efficiency, is appointed by a decree from the president of the university based on a nomination by the dean of the college or institute and the appointment is for a renewable two years tenure, and he/she is responsible in managing its scientific and administrative and financial affairs, and present to the dean a report on the department works at the end of each academic year."

The heads of colleges departments are considered of the elements of success of the administrative development process and leading of creativity and innovation in the university, on them lays the responsibility of directing the social and individual behaviors of the faculty members and the students towards capabilities increasing their efficiency in accomplishing the educational objectives. (Saleh \& Hassan, 2010). Through the organizational relationship between the higher administration in the colleges and the heads of departments and department faculty members, the foundation for the organizational culture for the department is but in place, which represent a miniature model of the organizational culture for the university and which reflects in its context the extent of strength or weakness of the prevailing organizational culture, where Alrawashda (2007) sees that the organization 
culture varies to a strong culture agreed upon by organization members and helps to improve their performance, and a weak culture leading to the carelessness and close-mindedness where an innovation discouraging atmosphere prevails.

As the strong culture cares about stimulating the workers and increasing their potential through providing the opportunity for them to participate in the decision making process within the organization and find a kind of cooperation and integration, and this culture helps in achieving the speed of response and interaction with the environment and getting rid of the routine processes and improvement of human relations, Alalfi (2010) points that the strong culture in the organization enables its members to commit and create, and participate in decision making which drives the accomplishment of a distinguished performance enabling the organization to achieve its goals, while the weak culture is usually found in the presence of a bad atmosphere that is not encouraging the sharing and cooperation and serious work, as well as leading to the spread of carelessness and serious slowness and some negative values and the presence of some sort of organizational voiding.

Hejazeen (2011) adds that there is a plurality in the culture patterns prevailing within the educational organizations, as in the bureaucratic culture pattern responsibilities are specified and work within it is organized and distributed and the chain of command and information flow takes a pyramidal shape, this culture depends on control and commitment, while the creative culture pattern is characterized by the existence of a work environment that assists creativity and its members are characterized with being adventurous in decision making facing challenges and the culture of strength. This type focuses on decisiveness and the administrator enjoys a presence and cares for himself and the ones loyal to him, yet clear in his/ her demands. And the culture of human sympathy which focuses on sympathy and service relationships, characterized with the sympathy of workers towards each other in work and admire each other and value achievements and feel belonging. And the culture of achievements where it focuses on success and growth and excellence, and is characterized by its workers feel of the importance and speed of accomplishing goals.

Each of Algerioti (2006), Kassab (2007), Alrawashda (2007), Salih \& Hassan (2010), Alamian (2010), Alalfi (2010), Hijazeen (2011), Dawood (2011), Mohammed \& Mursi (2012) and Almajali (2016) see that the organizational culture can be developed in the universities into an active culture through developing its different dimensions which are "vision, hypotheses, symbols, activities, standards, communications", on the vision level, the science and its applications must present the main obsession to the workers in the college, and the workers information must be changeable with every new discovery, provided that the administration engages the workers in 
making the crucial decisions, and the timings for the academic year activities are precisely applied, and the workers behaviors are always stemmed from their personal believes, on the hypotheses level, the characteristics of the work must not be looked at from a personal perspective, and the administration should thrive to activate the cooperation opportunities between the workers, and insure that the organizational phenomena of the workers reflect specific concepts, one the symbols level, the administration must thrive to solidify significant meanings for the workers, and care about specifying flags and marks which have special significance in work, and be careful reinforce its image with the workers, as on the activities level, the administration must encourage the state of scientific competitiveness and make sure to honor the creative ones, and host festivities and occasions to solidify its mission, as well as thriving to solidify the democratic approach through its activities.

On the standards level, regulations and rules must govern the workers behavior, and the guidelines, procedures and rules pertaining to the teaching process, teachers, students must be absolutely clear, given that the administrative relationships are govern by guides which can't be violated. In relation to communications, the communications between the boss and the subordinates in the university must be characterized with being easy and the unofficial relationships (personal and scientific) prevailing in the university, moreover, the communications between the university sectors must be conducted with simplicity and ease. Through those practices, an organizational culture that supports the creativity can be activated, as the administrative creativity "mostly includes finding growth and improvement to the administrative and technical development or plans and programs and procedures and rules of the administrative and academic work, as to be different than what it was, and directly and indirectly positively affect the administrative work and services provided to the people" (Alqasimi, 2002).

Discrimination can be made between three types of verified administrative creativity in universities, they are the administrative creativity on the individual level, the group level and the organization level; which are integrating with each other and all of which are crucial for today's organizations (Abu zaid, 2010). Where the active organizational culture contributes to achieving the creative behavior by the individual which in turn moves to the group and then to the organization as a whole, Alkasarnah (2011) points that the creative behavior is "the distinguished behavior practiced by the individual or the group in the workplace, and is a behavior preceding the creativity in its final form", and the group of creative behaviors which are practiced by the individuals of the organization through the organizational culture collectively achieve the administrative creativity. 


\section{Conclusion}

It can be said that the organizational culture achieve its highest goals through contributing in accomplishing the various administrative creativity dimensions, represented in "problem solving, decision making, ability to change, adventurous spirit and encouragement of creativity". The organizational culture contribute in assisting the individual in problem solving and decision making, enabling him/her to make a decisive decision in a relatively record time, and enabling him/her to discover problems in order to solve them. It try new ideas and ways to solve the problems and take separate stands against those problems in order to solve them. The organizational culture being able to make important decisions in case of the scarcity of available information. Furthermore, the organizational culture in individuals strengthen the ability to change making them more capable of frankly discussing the work rewards with their direct bosses, and more capable to find new ways to use the available resources or execute the work. It allocate time to follow up on their ideas and private projects, as well as strengthening their adventurous spirit and encourage creativity through the execution of the new ideas and encourage the suggestions submitted by others, providing incentives to attract the creative individuals, make sure of their continuity to work, and work on encouraging the individuals who think beyond their range of specialization.

\section{References:}

1. Almajali, Bashar Abdulmajeed (2016). Impact of organizational culture on the performance of workers from the point of view of the med-management: A case study on National Center Information Technology. The Arabian Journal of Sciences and Research Publishing Corporation - Palestine, F2, M7, 194-217.

2. Bruise, Warda and Zahiyya dabbab. (2016). Impact of organizational creativity on the job performance in the corporation. Fourth scientific symposium research: creativity in the business world-Research and Development Center on Human Resources - Rammah - Jordan, 81 96.

3. Alamyan, Mahmoud Suliman (2010).Organizational behavior in business organizations. Amman: Wail House.

4. Ali, Lateef Mohammed (2011). The creative thinking of the administrators and its relationship to administrative problems solving. Amman: Alyazouri Scientific House for Publishing and Distribution.

5. Atya, Tawfiq Tawfiq (2009) Administrative creativity and its relationship to job performance of general sector managers: a practical study on the ministries of Gaza Strip, College of Trade, Department of Business Administration, The Islamic University at Gaza. 
6. Gapar, Drazena and Mabic, Mirela.(2014). Creativity in higher education. Economic and social development: Book of Proceedings. Varazdin Development and Entrepreneurship Agency (VADEA).

7. Kassab, Zainab Mohammed (2007). Time management for heads of scientific departments in Aljazeera University in Sudan, Educational studies journal, M19, college of Education, Aljazeera University.

8. Council of higher education - General Secretariat. (1436H). The Council of higher education and universities system and regulations. Kingdom of Saudi Arabia.

9. Alzewdi, Majid bin Mohammed. Hejazeen, Nayel Eid. (2011). The prevailing culture in the Jordanian school classrooms - a critical ethnographic study. The Education Journal. 33. 219 - 246.

10. Abu zaid, Khalid. (2010). impact of the organizational power on the administrative creativity, Masters degree thesis, Middle East University, College of Business, Department of Business Administration.

11. Alqasimi, Omayma Abdulaziz (2002). The concept of the administrative creativity and its development. The third Arabian conference on administration: "The creative leadership and innovation in shadow of integrity and transparency" held in the Arabian Organization for Administration Development.

12. Altewaijri, Haila bint Mandil Mohammed. (2016). Administrative creativity and its relation to the job performance of the administrative workers in college of education in Braida in the University of Alqaseem: field study. The Arabian Gulf thesis - Saudi Arabia, s37, $m 140,79-101$.

13. Shagoura, Muneer. (2012). The management of change and its relationship with the administrative creativity for the high schools principals in Gaza provinces from the point of view of the teachers. $A$ non published master degree thesis. Azhar University: Gaza.

14. Hamza, Ibn Maatouq, and Zureik Darraji (2016). "Organizational culture: concept and characteristics." Journal of the Generation of Human Sciences - Center for the generation of scientific research Algeria 22: 173 - 180.

15. Murad, Ait Mohammed. (2016). International Conference on Creativity and Creativity in Business - $R \& D$ Center - Human Resources - Ramah - Jordan, Amman, 124-137.

16. Mousa, Adel. (2013). The Effect of Administrative Innovation on Human Resources Management in Small and Medium Enterprises, Master Memo, Qasidi University, Marbah, Ouargla, Algeria.

17. Alqarioti, Muhammad Qasim (2010) Organization and Organization Theory, Amman: Wael Publishing House. 
18. AlKurdi, Ahmed (2006) Organizational culture, the main axes for the development of organizational behaviour.

19. Osama, Khairi (2012). Department of Innovation and Innovation, Dar Al-Raya, Amman, Jordan.

20. Dawood, Abdulaziz Ahmed. (2011). Organizational culture and administrative creativity for the directors of public secondary schools "field study in Kafr El-Sheikh". Journal of Faculty of Education, Ain Shams University. (2) .9-89.

21. Mohammed, Mursi, Maher and Omar (2012) organizational culture and its relation to the administrative creativity of the administrative leaders. The scientific journal of the Faculty of Education, p. 28, 2, April: Assiut.

22. Alrawashda, Khalf Suleiman. (2007). School Decision Making and a Sense of Security and Organizational Loyalty, Amman. Dar Al Hamed.

23. Alalfi, Tariq Abu al-Attar. (2010). The role of organizational culture in achieving the strategic plan for Egyptian education. Field study on general secondary schools. Journal of Faculty of Education, Banha, Egypt. Number 85.

24. Saleh Ahmad, Hassan and Riad. (2010). The humanitarian needs of the heads of departments at Anbar University and their relation to the organizational climate of these departments. Anbar University Journal of Humanities - Iraq, p. 3, pp. 789-840.

25. Alfarawi, Alazzawi, Nagam. (2015). Active Management. International Forum for Creativity and Organizational Change in Modern Organizations: Study and Analysis of National and International Experiences. 18-19/5/2011. University of Saad Dahlab. Algeria.

26. Alamyan, Mahmoud Suleiman. (2004). Organizational Behavior in Business Organizations. 